\title{
A rede social e assistencial e a garantia de direitos: proteção ou (re)vitimização?
}

\section{Socio assistence network and a system of guarantee of rights: protection or revitimization?}

Lígia Maria Vezzaro Caravieri* Hilda Rosa Capelão Avoglia**

\section{Resumo}

Considerando a legislação brasileira que rege os direitos de crianças e adolescentes, neste caso, o Estatuto da Criança e do Adolescente (ECA) e o Sistema Único de Assistência Social (SUAS), enquanto políticas que organizam os serviços sócio assistenciais no Brasil, o presente artigo tem como objetivo refletir sobre a atuação dos profissionais diante de situações de violação de direitos de crianças e adolescentes e sua relação com os demais serviços que compõem a rede socioassistencial e o Sistema de Garantia de Direitos. Para tanto, partimos da experiência do Centro Regional de Atenção aos Maus Tratos na Infância do ABCD (CRAMI), organização social que oferece atendimento psicossocial e proteção de crianças e adolescentes vítimas de violência doméstica, nos municípios de Santo André, São Bernardo do Campo e Diadema, na Região do Grande ABC/SP. A legislação oferece

* Psicóloga, especialista em Violência contra Crianças e Adolescentes, pelo Laboratório da Criança - LACRI. Coordenadora do Centro Regional de Atenção aos Maus Tratos na Infância - CRAMI - Grande ABC-SP

* Professora Doutora, docente do Programa de Pós-Graduação em Psicologia da Saúde da Universidade Metodista de São Paulo e do Programa de Pós- Graduação em Psicologia e Políticas Públicas da Universidade Católica de Santos. 
caminhos que facilitam o enfrentamento dos desafios impostos aos que trabalham junto a essa realidade.

Palavras-chave: Violência doméstica - Violação de direitos - Crianças e Adolescentes - Estatuto da Criança e do Adolescente (ECA).

\section{Abstract}

Considering the Brazilian legislation that governs the rights of children and adolescents, in this case, the Statute of the Child and Adolescent (ECA) and the Unified Social Assistance System (SUAS), as policies that organize social assistance services in Brazil, the present article Has as objective to reflect on the professionals' actions in the face of situations of violation of the rights of children and adolescents and its relationship with the other services that make up the social assistance network and the System of Guarantee of Rights. To do so, we start with the experience of the Regional Center for Attention to Child Abuse in ABCD (CRAMI), a social organization that provides psychosocial care and protection of children and adolescents victims of domestic violence in the municipalities of Santo André, São Bernardo do Campo and Diadema, in the Region of the Great ABC / SP. The legislation offers ways that facilitate the confrontation of the challenges imposed on those who work in this reality.

Key words: Domestic violence - Rights violation - Children and adolescents - Statute of Child and the Adolescent.

Nossa experiência psicológica com crianças e adolescentes que têm seus direitos violados tem apontado para a necessidade de reflexões, discussões e, talvez, modificações, no trabalho que envolve políticas públicas relativas a essa população. Entre essas necessidades destacam-se as ações junto aos Conselhos Tutelares, a necessidade da atuação em rede, além da efetividade do Sistema Único de Assistência Social (SUAS).

Também é importante destacar, que nessa prática, temos observado psicólogos que vêm tradicionalmente de uma formação acadêmica de atuação mais individualizada e que, muitas vezes se deparam com dificuldades em definir suas ações profissionais, dificuldades em se adaptarem a atendimentos diferenciados ou atuações em equipes multidisciplinares; enfrentam dilemas ante o sigilo profissional, dificuldades na elaboração de relatórios a serem 
dirigidos ao Poder Judiciário, bem como conflitos com seus valores pessoais - naquilo que deve ou não ser considerado violência.

Essas questões estão longe de serem consideradas como simples manejo profissional; há ainda um sistema que também não facilita esse fluxo de trabalho. Os órgãos com os quais o psicólogo tem de compartilhar também não têm respostas satisfatórias que garantam a proteção dessas crianças e adolescentes que sofrem violência. Há uma demanda maior que a capacidade de atendimento, uma infra-estrutura precária dos serviços, morosidade das ações operacionalizadas pela rede, além que é visível a impunidade de agentes agressores.

As reuniões de rede frequentemente parecem campos de batalha, com acusações e cobranças mútuas, no qual cada profissional ou serviço parece querer impor sua verdade própria, seu ponto de vista com relação ao caso que, na realidade vivencia um sofrimento. A complexidade destas relações nos aponta para a premissa de que aquele que não compartilha do mesmo parecer, é visto como incompetente ou desqualificado. De modo que, o funcionamento contumaz e insatisfatório de tramitação de cada caso acaba por propiciar um terreno fértil para reprodução da violência nas relações institucionais e nos próprios atendimentos.

Isto então nos conduz a uma indagação: será que as o sistema público protege ou (re) "vitimizam" essas crianças e adolescentes que sofrem violência?

A fim de refletirmos sobre isso, é interessante retomarmos brevemente alguns conceitos que norteiam a legislação brasileira na área da infância, assim como políticas públicas formuladas para efetivação de proteção de crianças e adolescentes que tiveram seus direitos violados.

\section{Estatuto da Criança e do Adolescente: formulação e aplicação}

O Estatuto da Criança e do Adolescente (ECA, 1990) é uma lei popular; e para Cury, Silva e Mendez (1992) essa lei é fruto do esforço conjunto de pessoas e comunidades empenhadas na defesa e na promoção das crianças e adolescentes no Brasil. A partir de 1986, quando o país se preparava para redigir uma nova Consti- 
tuição, teve início um movimento de entidades da sociedade civil para influenciar a Assembléia Nacional Constituinte a favor da infância e adolescência. Durante as mobilizações, foram formados dois grupos distintos reunindo entidades que trabalhavam com a causa: a Comissão Criança e Constituinte e o Fórum Nacional de Defesa dos Direitos da Criança e do Adolescente, que convocava a população a participar, gerando mais de dois milhões de assinaturas que foram recolhidas para a criação de duas emendas populares. O resultado foi a inclusão do Artigo 227 na Constituição Brasileira, que versa o seguinte:

"É dever da família, da sociedade e do Estado assegurar à criança e ao adolescente, com absoluta prioridade, o direito à vida, à saúde, à alimentação, à educação, ao lazer, à profissionalização, à cultura, à dignidade, ao respeito, à liberdade e à convivência familiar e comunitária, além de colocá-los a salvo de toda forma de negligência, discriminação, exploração, violência, crueldade e opressão" (BRASIL, 1986, art. 227).

A legislação brasileira considera 'criança' uma pessoa com até 12 anos de idade incompletos, e considera adolescente aquele entre 12 e 18 anos de idade. Diferentemente a "Convenção Internacional dos Direitos da Criança" considera criança uma pessoa menor de 18 anos, a menos que a lei do país estabeleça uma idade menor como sendo a maioridade. Assim, conforme Castro (2010) no Estatuto da Criança e Adolescente (ECA) a criança e o adolescente são vistos como sujeitos de direitos e pessoas em condição peculiar de desenvolvimento, garantindo ainda proteção especial àqueles que se encontram em situação de risco social e pessoal. Desta forma, o Estatuto contempla estratégias voltadas às políticas sociais articulando família, sociedade e poder público na busca de medidas de proteção integral à criança e ao adolescente.

No caso dos psicólogos da região do Grande ABC, SP, o estudo realizado por Brambilla e Avoglia (2010) indica que estes percebem o ECA como uma ferramenta necessária para assegurar os direitos desse segmento da população, com destaque para aqueles que se encontram em situação de vulnerabilidade social, ampliando e in- 
tegrando o campo de atuação na proposição e no acompanhamento de ações favoráveis a saúde humana, constituindo-se assim, em um aliado para a consolidação do trabalho diante dos conflitos interpessoais, fortalecendo a construção de políticas públicas que sustentem ainda mais a rede integral de atenção.

\section{A descentralização das ações}

A Constituição Federal de 1988 reconheceu o Município como ente autônomo da Federação, mas, não independente. Nesse sentido, municipalizar é permitir, por força da descentralização político-administrativa, que determinadas decisões políticas e determinados serviços sejam encaminhados e resolvidos no âmbito do Município, sem excluir a participação e cooperação de outros entes da Federação (União e Estados) e da sociedade civil organizada.

Transportando a prerrogativa acima para a área da Infância e Juventude, a lei 8.069/90, o Estatuto da Criança e do Adolescente, também prevê responsabilidades para todas as instâncias acima citadas. Inclusive, como mostrou relatoria feito pela ANDI e INSTITUTO VOTORANTIM (2005), este é um dos elementos que vem contribuindo de forma decisiva para garantir a eficácia operacional do ECA, ou seja, a plena definição de responsabilidades, por parte do estado e da sociedade civil, na implementação e manutenção em todo o território nacional, de colegiados a quem cabe zelar pela promoção e pela defesa dos direitos das novas gerações.

O Estatuto aborda com propriedade a necessidade da participação e envolvimento tanto do poder local quanto do poder central para a garantia de direitos de crianças e adolescentes. O próprio Estatuto (ECA, 1990, art. 86) expõe que a política de atendimento dos direitos da criança e do adolescente far-se-á por meio de um conjunto articulado de ações governamentais e não-governamentais, da União, dos Estados, do Distrito Federal e dos Municípios.

O citado artigo é resultado dessa concepção de autonomia dos entes que integram a Federação, assim, a política de atendimento às crianças e aos adolescentes não será realizada com exclusividade pelos Municípios, mas em sua permanente articulação com a União, Estados e entidades não-governamentais. Desta maneira, a política de atendimento à criança e ao adolescente é estruturada em 
princípios da hierarquia, como a União, Estado, Município, além de princípios da complementaridade, que estabelecem a articulação entre as ações governamentais e não governamentais em todos os níveis Digiácomo e Digiácomo (2010). Estes aspectos se constituem na tradução de dois princípios constitucionais (Lei n.8742. BRASIL, 1993) que precisam ser reconhecidos, a saber:

a) Descentralização político-administrativa: competências e atribuições específicas e complementares para a União, os Estados e os Municípios;

b) Participação da população, por meio de suas organizações representativas.

Nesta divisão de responsabilidades, cada um dos princípios da hierarquia acima mencionada tem atribuições específicas. Assim sendo, conforme Pontes Jr (1993) a União não executa diretamente programas de atendimento à criança e ao adolescente, cabendo-lhe a coordenação global da política, definição de normas gerais de ação, fiscalização das políticas e controle das ações. Já o Estado, pode vir a executar ações diretas, como os atendimentos, mas apenas quando estas extrapolam a capacidade do município. Na realidade, são ações que somam ao trabalho realizado pelo Poder Público Municipal, comunidades e organizações não-governamentais. Entretanto, destacamos que suas principais atribuições são a coordenação da política de maneira complementar à União e a adaptação das normas federais à sua realidade.No que tange aos Municípios, por meio do Governo Municipal, da comunidade e das organizações não-governamentais, cabe a execução direta dos atendimentos a crianças e adolescentes e a coordenação no âmbito local. A população organizada participa da formulação, coordenação, execução, fiscalização e controle da política municipal de atendimento à criança e ao adolescente, ou seja, poder público e sociedade civil compartilham responsabilidades e ações efetivas de atendimento.

Não é possível abordar as políticas voltadas para a criança e o adolescente, sem destacar o importante papel dos Conselhos Tutelares, também estabelecidos pelo Estatuto da Criança e do Adolescente. Conforme expõem Digiácomo e Digiácomo (2010) é necessário ampliar mais a participação da sociedade civil nas instâncias democráticas dos Conselhos Tutelares, incumbido de fisca- 
lizar o funcionamento de todo o sistema de atendimento à infância e juventude (podendo inclusive requisitar serviços públicos para viabilizar a execução das medidas que aplica) e dos Conselhos dos Direitos da Criança e do Adolescente.

\section{A infância brasileira e o Sistema de Garantia de Direitos}

A experiência de implementação de conselhos é nova, ainda mais, de conselhos voltados à formulação de políticas públicas que garantam os direitos de crianças e adolescentes. Isto se justifica, pois, é relativamente recente a concepção de que crianças e adolescentes são pessoas em condições peculiares de desenvolvimento, com necessidades específicas, e não adultos em miniaturas. Sobre essa questão, o Estatuto da Criança e do Adolescente prevê que:

"Nenhuma criança ou adolescente será objeto de qualquer forma de negligência, discriminação, exploração, violência, crueldade e opressão, punido da forma da lei qualquer atentado, por ação ou omissão, aos seus direitos fundamentais" (ECA, 1990, art. 5º).

A mesma lei afirma ainda no seu art. $4^{\circ}$, que

“É dever da família, da comunidade, da sociedade em geral e do poder público assegurar, com absoluta prioridade, a efetivação dos direitos referentes à vida, à saúde, à alimentação, à educação, ao esporte, ao lazer, à profissionalização, à cultura, à dignidade, ao respeito, à liberdade e à convivência familiar e comunitária" (ECA, 1990, art. 4º.).

Observamos, no entanto, que as crianças e adolescentes brasileiros sofrem toda série de violações de seus direitos, seja por parte da família, da sociedade ou do Estado. A violação dos direitos por parte da família pode ser observada pelo alto índice de ocorrência de violência doméstica praticada contra crianças e adolescentes, conforme mostra nossa experiência junto ao CRAMI - Centro Regional de Atenção aos Maus Tratos na Infância do ABCD. Em levantamento interno por nós realizado, foi possível identificar que a instituição atendeu, no ano de 2012, 688 famílias, nas quais há registros oficiais de ocorrência de situação de violência doméstica contra crianças e adolescentes. 
Cabe destacar que estas informações foram observadas na nossa instituição (CRAMI), a qual atende uma parcela das notificações dos Conselhos Tutelares, pois muitas famílias são encaminhadas para outros serviços. Sobre esse aspecto o Laboratório da Criança da Universidade de São Paulo (LACRI/ USP, 2007) cita que apenas um, em cada dez casos, são notificados, podemos vislumbrar a dimensão da problemática de violação de direitos de crianças e adolescentes cometidos pelas próprias famílias.

Outro importante exemplo dessa violação de direitos é o trabalho infantil, conforme Rizzini (2000) que ao elaborar uma análise sobre o tema, em 1995, o Brasil contava com aproximadamente oito milhões de crianças e adolescentes de 5 a 17 anos trabalhando. A autora alertou para o fato de que esta situação acaba por afastar a criança e o adolescente da escola, pois a longa jornada de trabalho é um dos fatores que levam a evasão escolar, visto que o adolescente muitas vezes substitui a escola pelo trabalho.

Frente ao contexto apresentado nos parece significativo ressaltar a importância de órgãos como os Conselhos Tutelares, que zelam pela efetivação dos direitos previstos pelo Estatuto da Criança e do Adolescente, pois uma vez constatada situação de violação dos direitos, o Conselho Tutelar pode, por exemplo, aplicar medidas de proteção, conforme previsto no Artigo 101 do ECA (1990).

A existência do Conselho Tutelar também não garante na prática a efetivação dos direitos previstos pelo Estatuto da Criança e do Adolescente (ECA), visto que, muitas vezes, possui infra-estrutura, pessoal qualificado, além de enfrentar falta de políticas públicas que contemplem a demanda atendida pelo órgão.

\section{Conhecendo os Conselhos Tutelares}

A criação dos Conselhos Tutelares é prevista pelo Estatuto da Criança e do Adolescente (lei 8.069, de 13 de julho de 1990, que entrou em vigor em 14 de outubro de 1990), sendo um órgão permanente e autônomo, não jurisdicional, encarregado de zelar pelo cumprimento dos direitos das crianças e adolescentes. Esta definição, por si só, não se apresenta como esclarecedora, sendo necessário entender cada uma das especificidades acima citadas. 
Assim, o fato de se constituir em um órgão permanente e autônomo, quer dizer que é um órgão público, criado por lei, que integra definitivamente o conjunto das instituições brasileiras, estando, portanto, sujeito e subordinado ao ordenamento jurídico do país e que, em suas decisões, tem autonomia para desempenhar as atribuições que lhe são confiadas pelo Estatuto Federal que o instituiu (SEDA, 2005). Uma vez criado por lei e instalado, o Conselho Tutelar não pode ser desfeito ou desativado, sendo possível a mudança apenas dos conselheiros por meio de seus mandatos temporários.

Ao apontarmos o Conselho Tutelar como sendo um órgão não jurisdicional, significa que não integra o Poder Judiciário, exercendo, portanto, funções de caráter administrativo, dependendo da órbita do Poder Executivo, em que fica vinculado para os efeitos administrativos da sua existência como órgão que executa funções públicas (SEDA, 2005). O conselheiro tutelar não deve ser confundido com o juiz da infância e juventude, nem tão pouco com a figura do comissário de menores, pois é encarregado pela comunidade de zelar pelo cumprimento dos direitos da criança e do adolescente definidos pelo ECA, uma vez que os conselheiros tutelares são eleitos pela comunidade para desempenhar sua função.

Segundo a legislação, o Estatuto da Criança e Adolescente (BRASIL, 2012 art. 132) todo município brasileiro deve contar com, no mínimo um Conselho Tutelar funcionando, sendo que este número que varia de acordo com o contingente populacional, bem como, todo município deve criar seu conselho municipal.

\section{Conhecendo o Sistema Único de Assistência Social (SUAS)}

Conforme a Secretaria Desenvolvimento Social do Estado São Paulo (s/d a.) a Assistência Social é um direito do cidadão e dever do Estado, instituído pela Constituição Federal de 1988. A partir de 1993, com a publicação da Lei Orgânica da Assistência Social - LOAS, é definida como Política de Seguridade Social, compondo o tripé da Seguridade Social, juntamente com a Saúde e Previdência Social, com caráter de Política Social articulada a outras políticas do campo social. Tem objetivo de garantir a proteção social à família, à infância, à adolescência, à velhice; amparo a crianças e adolescentes carentes. 
Conforme essa mesma secretaria, o Sistema Único de Assistência Social (SUAS) é um sistema público instituído em 2005, numa proposta descentralizada e participativa, que tem por função a gestão do conteúdo específico da Assistência Social no campo da proteção social brasileira. Com um modelo de gestão participativa, articula os esforços e recursos dos três níveis de governo para a execução e o financiamento da Política Nacional de Assistência Social (PNAS), envolvendo diretamente as estruturas e marcos regulatórios nacionais, estaduais, municipais e do Distrito Federal. Coordenado pelo Ministério do Desenvolvimento Social e Combate à Fome (MDS), o Sistema é composto pelo poder público e sociedade civil, que participam diretamente do processo de gestão compartilhada.

O SUAS organiza as ações da assistência social em dois tipos de proteção social. A mesma Secretaria de Desenvolvimento Social do Estado São Paulo (s/d b.) entende que a primeira - Proteção Social Básica, é destinada à prevenção de riscos sociais e pessoais por meio da oferta de programas, projetos, serviços e benefícios a indivíduos e famílias em situação de vulnerabilidade social. A segunda é a Proteção Social Especial, destinada as famílias e indivíduos que já se encontram em situação de risco e que tiveram seus direitos violados por ocorrência de abandono, maus-tratos, abuso sexual, uso de drogas, entre outros aspectos.

A Proteção Social Especial é executada pelo Centro de Referência Especializado da Assistência Social (CREAS), serviço municipal responsável por garantir a inclusão da família e dos indivíduos que sofreram a violência na rede sócio assistencial do município.

Atualmente, promove-se uma discussão quanto a fato do CREAS atender diretamente seu público alvo ou se pode "terceirizar" este serviço, cabendo-lhe o papel de referência, contra-referência, articulação e monitoramento das ações.

Polêmicas a parte, é na Proteção Social Especial que entra a atuação do CRAMI do ABCD, organização escolhida para ilustrar algumas particularidades da intervenção do psicólogo na temática da violência contra crianças e da interseção com a rede de serviços e do Sistema de Garantia de Direitos, atuação esta que pode levar à proteção ou a revitimização. 


\section{A atuação do CRAMI}

O CRAMI é uma organização não governamental que tem como missão "propiciar atendimento psicossocial a crianças e adolescentes vítimas de violência doméstica e desenvolver ações preventivas que lhes possibilitem defesa e proteção incondicional".

Sua equipe é composta por assistentes sociais e psicólogos, que atendem as crianças e adolescentes que sofreram a violência, suas famílias e o autor da agressão. Como critério de atendimento, recebe casos de violência física, sexual, psicológica, negligência e abandono ocorridos no ambiente doméstico. No caso da violência sexual especificamente, também atende casos de exploração sexual comercial e abuso sexual extra familiar.

A organização também realiza ações preventivas com a comunidade e ações de capacitação junto a profissionais, como estratégias de enfrentamento à violência doméstica e sexual contra crianças e adolescentes. A atuação do psicólogo no CRAMI é ampla, pois ele atua junto com o assistente social para avaliação psicossocial do caso e definição de plano de atendimento. As atuações em conjunto com o assistente social também ocorrem nas intervenções domiciliares e nos grupos de orientação com os pais ou responsáveis, cada um com atribuições específicas, dentro do seu campo de conhecimento. O psicólogo realiza atendimentos em grupos, sendo respeitadas as faixas etárias e a tipologia da violência. O CRAMI tem um diferencial que é o atendimento aos autores da agressão, inclusive aos abusadores sexuais.

Como a existência do CRAMI é anterior a instauração dos Conselhos Tutelares na região que atua ${ }^{1}$, inicialmente atendia casos notificados pela comunidade, por profissionais de diversas áreas, como na saúde, na educação e pelo Poder Judiciário. Após a implantação dos Conselhos Tutelares, houve uma mudança no fluxo de encaminhamento, o CRAMI passou a receber apenas as famílias encaminhadas pelos Conselhos Tutelares, pelo Poder Judiciário e pela Delegacia de Polícia. Houve uma grande resistência da comunidade e do meio profissional em aceitar o Conselho Tutelar como

\footnotetext{
1 Atualmente o CRAMI atua nos municípios de Santo André, São Bernardo do Campo e Diadema.
} 
o canal de denúncia, por desconhecimento das atribuições do órgão, do caráter anônimo da notificação e até mesmo pela descrença na atuação do Conselheiro Tutelar. Infelizmente a descrença é algo ainda muito presente, sendo o Conselho Tutelar,de certa forma, ainda malvisto, por grande parte dos profissionais que atuam cotidianamente com crianças e adolescentes.

Com a promulgação do SUAS e implantação do CREAS nos municípios, os fluxos de atendimento foram reformulados, sendo que CRAMI passou a receber as famílias encaminhadas pelo CREAS. Parece uma modificação simples, mas na prática foi um processo confuso, pois os CREAS's começaram a atuar com equipes defasadas, infra estrutura inadequada e sem fluxo redefinido. Os Conselhos Tutelares, que até então podiam encaminhar as famílias diretamente ao CRAMI, passaram a ter que enviar ao CREAS para atendimento, que após avaliação do caso encaminhavam ao CRAMI.

Neste processo, as famílias chegavam ao CRAMI após meses da ocorrência da notificação aos Conselhos Tutelares, já desgastados pelos sucessivos relatos do episódio violento, pelo vai e vem aos serviços, pela longa espera pelo atendimento, entre outros aspetos. Como desencadeador desse processo, verificamos que, na realidade, ou o quadro de violência estabelecido havia se agravado, ou então, a família já entrara em um estado de acomodação e banalização da violência. Diante destas considerações, explicamos de onde advém o título deste artigo: "A rede sócio assistencial e o Sistema de Garantia de Direitos: proteção ou (re) vitimização?"

\section{Considerações finais}

Diante do complexo cenário descrito acima temos uma ideia de como as pessoas envolvidas na situação de violência, sejam elas vítimas, testemunhas ou autoras da agressão, chegam ao serviço psicológico. O atendimento a casos de violência coloca o psicólogo em um dilema quanto à quebra de sigilo, a relação próxima com os órgãos da justiça, a discussões contínuas com os diversos serviços que compõem a rede de atendimento.

A atuação profissional em casos de violação de direitos de crianças e adolescentes propõe desafios ao psicólogo, que envolve uma demanda crescente, geralmente maior que a capacidade de 
atendimento, permeada por contatos diários com as mais diversas formas de sofrimento humano. O psicólogo tem o desafio de ultrapassar uma atuação conservadora, para adaptar-se e propor novas formas de enquadre, que contemplem o atendimento a uma demanda que não é espontânea. Frequentemente o "atendido" está em psicoterapia por determinação judicial e a demanda terá de ser criada na relação psicólogo-cliente. Em se tratando de situação de violência contra crianças e adolescentes, o sigilo terá de ser rompido para garantir a proteção e atender às exigências legais.

Aliás, outro desafio para o profissional. O seu campo de atuação indica a necessidade de ser mais amplo, com a produção de conhecimentos que extrapolem a própria Psicologia e contemple a magnitude de outras áreas do saber, que muito contribuem com os aspectos legais, resoluções, políticas públicas, entre outros.

\section{Referências}

ANDI- AGÊNCIA DE NOTÍCIAS DOS DIREITOS DA INFÂNCIA/ INSTITUTO VOTORANTIM. Relatório- a mídia dos jovens. Brasília, Ano 8 , n. 11, Jun 2005

BRAMBILLA, B. B.;AVOGLIA, H. R. C. O Estatuto da criança e do adolescente e a atuação do psicólogo. Psicólogo InFormação, v. 14. n.14, p. 102-121, 2010.

BRASIL . Lei n.8742. Lei Orgânica da Assistência Social , Cap.II “Dos Princípios e das Diretrizes" Seção II, art.5 , 1993.

BRASIL. Presidência da República. Casa Civil. Subchefia para Assuntos Jurídicos. Lei $n^{\text {o 12.696, de }} 25$ de jul de 2012. Altera os arts. 132, 134, 135 e 139 da Lei no 8.069, de 13 de julho de 1990 (Estatuto da Criança e do Adolescente), para dispor sobre os Conselhos Tutelares. Disponível em: http://www.planalto.gov.br/ccivil_03/_ato20112014/2012/lei/112696.htm. Acesso em: 11 ago 2016.

BRASIL. Constituição da República Federativa do Brasil, de 5 de outubro de 1988. BRASIL. Lei federal no 8.069/90, de 13 de julho de 1990 (Estatuto da Criança e do Adolescente).

CASTRO, D. S. P Construção de um saber e responsabilidade social na Psicologia: o conselho tutelar em foro. São Paulo: Instituto de Psicologia da USP, 2002.

CEATS / FIA - Centro de Empreendedorismo Social e Administração em Terceiro Setor da Fundação Instituto de Administração. Pesquisa Conhecendo a Realidade, 2007. CENTRO REGIONAL DE ATENÇÃO AOS MAUS TRATOS NA INFÂNCIA DO ABCD. Relatório de Atividades 2012. Santo André-SP, CRAMI, 2013. 
CURY, M; SILVA, A.F ; MENDEZ, E.G. Estatuto da Criança e do Adolescente Comentado. São Paulo: Malheiros Editores, 1992.

DIGIÁCOMO, M.J.; DIGIÁCOMO, I.A. Estatuto da Criança e do Adolescente Anotado e Interpretado. Lei no 8.069, de 13 de julho de 1990 (atualizado até a Lei no 12.010, de 03 de agosto de 2009). Ministério Público do Estado do Paraná. Centro de Apoio Operacional das Promotorias da Criança e do Adolescente. Curitiba, 2010 LACRI/ USP- Laboratório de Estudos da Criança. Ponta do Iceberg. 2007. Disponível em: www.ip.usp.br/laboratórios/lacri/iceberg.htm\#2 . Acesso em 10 jun 2016.

PAULA, P.A.G. Um órgão de atendimento, In: Ouvindo conselhos: democracia participativa e direitos na infância na pauta das redações brasileiras. São Paulo:Cortez, 2005. (Série mídia e mobilização social, 8).

PONTES JR, F. Conselho de Direitos da Criança e Adolescente. São Paulo: Malheiros, 1993

RIZZINI, I. Pequenos trabalhadores do Brasil. In: PRIORE, M. (Org.). História das Crianças no Brasil. São Paulo: Contexto, 2000, p. 376-406.

SECRETARIA DESENVOLVIMENTO SOCIAL DO ESTADO SÃO PAULO. Sistema Único de Assistência Social - SUAS. (s/d a.). Disponível em: http://www.desenvolvimentosocial.sp.gov.br/portal.php/assistencia_sistema. Acesso em: 03 jul 2016. SECRETARIA DE DESENVOLVIMENTO SOCIAL DO ESTADO SÃO PAULO . Proteção Básica. (s/d b.). Disponível em: http://www.desenvolvimentosocial.sp.gov. br/portal.php/assistencia_basica . Acesso em: 03 jul 2016.

SEDA, E. Estatuto da Criança e do Adolescente comentado para cidadãos das comunidades urbanas, rurais e indígenas. 1. ed. Rio de Janeiro:Edição Adês, 2005. SISTEMA Único de Assistência Social . Disponível em http://www.mds.gov.br/ assistenciasocial/suas Acessado em 10 abr. 2016.

Contato dos autores:

Hilda Avoglia: Rua José Benedetti, 237 - apto. 102. SC do Sul, S.P. Email: hildaavoglia@terra.com.br

Recebido em 10/02/2016

Aceito em: 11/11/2016 